\title{
Contributive Justice: An exploration of a wider provision of meaningful work
}

\author{
Cristian Timmermann \\ cristian.timmermann@gmail.com
}

This is an author accepted version of a manuscript which has been published in:

"Social Justice Research"

This version is distributed under the Creative Commons Attribution 3.0 Netherlands License, which permits unrestricted use, distribution, and reproduction, in any medium, provided the original work is properly cited.

Please cite this publication as follows:

Timmermann, Cristian. 2018. "Contributive Justice: An Exploration of a Wider Provision of Meaningful Work." Social Justice Research 31 (1):85-111

The final publication is available at Springer via:

http://doi.org/10.1007/s11211-017-0293-2 


\section{Contributive Justice: An exploration of a wider provision of meaningful work}

Abstract: Extreme inequality of opportunity leads to a number of social tensions, inefficiencies and injustices. One issue of increasing concern is the effect inequality is having on people's fair chances of attaining meaningful work, thus limiting opportunities to make a significant positive contribution to society and reducing the chances of living a flourishing life and developing their potential. On a global scale we can observe an increasingly uneven provision of meaningful work, raising a series of ethical concerns that need detailed examination. The aim of this article is to explore the potential of a normative framework based upon the idea of contributive justice to defend a fairer provision of meaningful work.

Keywords: labour conditions; capabilities; de-skilling; human flourishing; social justice; knowledge economy; poverty.

\section{Introduction}

Everyday human well-being can be considerably improved by making meaningful work more widely available and by offering additional opportunities to contribute positively to society. The recent revival and expansion of the concept of "contributive justice" is a valuable tool when arguing for a fairer provision of meaningful tasks, doing one's share of tedious tasks, a fairer competition of ideas and capacity-building. The first aim of this article is to explore the demands proposed by this concept. The second aim is to show that the concept of contributive justice can highlight injustices insufficiently addressed by traditional concepts of social justice, such as distributive justice, commutative justice (i.e. justice in transaction) and restorative justice.

I pursue these goals first by briefly discussing why securing meaningful work is important for social welfare; second, examining what contributive justice demands; third, offering a brief defence of these demands; fourth, listing some of the negative implications of adhering to this notion of justice; and finally, drawing some conclusions on the potential benefits and disadvantages of a wider use of the concept.

\section{Why should we worry about the inherent quality of work?}

Here I understand 'work' as a very broad range of activities undertaken for present or in preparation for future remuneration in payment or in kind; this is in contrast to hobbies or charitable activities, which 
are undertaken in and for themselves with no requirement for any form of remuneration at any time. Due to the limited availability of land and growing economic interdependence, selling one's labour is increasingly becoming the norm, calling for an evaluation of the demands for a fairer provision of meaningful work within the labour market.

Work as here understood is thus the conscious activity at which adults spend most of their time, especially when taking into consideration the time consumed preparing, recovering and traveling to and from workplaces. What is particularly important for assessing the social justice dimension of work is the fact that the design of workplaces, the availability of sufficient social insurance and the general situation of the job market have an enormous impact upon the provision of meaningful work and allow substantial room for improvement of the work experience. Moreover, market economies create huge financial incentives to exploit vulnerable population segments, such as cheap labour, to perform repetitive, demeaning and health-deteriorating tasks (Gomberg 2017), particularly in situations in which companies need not fear backlashes in the form of consumer boycotts and loss of reputation. A failure to protect workers from exploitation overwhelmingly affects workers who are in a vulnerable position or, more generally, people who invoke insufficient sympathy in large consumer groups and from powerful political representatives. The factors that can reduce the willingness or ability to socially relate to the exploited groups include, among others, racial discrimination, out-of-sight production facilities, ignorance, apathy, wishful thinking and simple convenience.

There are a number of reasons why addressing the quality of work is a major concern in terms of social justice. First, for the overwhelming majority of the world's population, work is the only means to secure subsistence for themselves and others and is thus a necessity (Roessler 2012, 76-77; Gourevitch 2016, 313-14). Second, due to the extensive time in which people are engaged in work, their tasks affect their mental and physical well-being, the skills they develop and the extent to which they become empowered in immediate and wider social circles (cf. Deranty and MacMillan 2012, 395 402; Gheaus and Herzog 2016, 74-75). Policy changes affecting the quality of work have an enormous effect upon human welfare because work that can be characterized as meaningful allows people to develop skills, receive recognition and often enables them to be the critical citizens required by wellfunctioning democracies. Third, workplaces can be redesigned so that meaningful tasks are provided more evenly among workers, as long as everyone does a fair share of tedious work (Gomberg 2007, 75-90). The fact that meaningful work is nowadays a scarce and most unevenly provided good obliges people to compete for the better jobs (Gomberg 1995), whilst continuous competition may itself be detrimental to the quality of work. Fourth, a lack of intellectual stimulation may cause cognitive harm, leading to apathy and boredom (May et al. 2014, 653), ultimately affecting mental heath. Fifth, the inability to secure sufficient leisure time has a strong negative effect on job satisfaction in societies that set a high value on family life (Valente and Berry 2016). Such an outcome is easily avoidable; tax incentives could be used to make it much more attractive for employers to hire additional workers than to overburden their employees with excessive work hours. Similarly, a job market that demands a high rate of mobility does not allow people to maintain a sufficiently wide social network. This is a problem that could be tackled with the development of communication technologies, now already allowing a reduction of the amount of work-related travelling; and regulations could be implemented to give 
highly mobile workers travel allowances and additional discretionary days off. Sixth, the market possibly incentivizes employers to offer a smaller group the benefits of challenging and self-directed work and to a larger group the disadvantages of monotonous, closely-supervised and intellectually undemanding work (Lane 1991, 289). It is easier to control workers who are less skilled as they are easier to replace and therefore have less bargaining power.

Low-quality jobs also have a strong effect on how workers interact with each other and with people outside their workplaces. Studies have shown that people engaged in dull work for a prolonged period will most likely also pursue intellectually undemanding activities during their leisure time (Kohn and Schooler 1982, 1269; Schwartz 1982, 636-39), ultimately reducing their ability to positively contribute to wider social and political well-being, limiting their individual flourishing, making them much more vulnerable to political propaganda and insufficiently capable of undertaking civil action to defend democratic rights and to demand the development of good relations among nations. Jobs that leave workers too exhausted, trigger a state of apathy, or require excessive or irregular working hours, not only limit the opportunity to take part in social and family life, but may also hinder workers' effective participation both in civil society and in the trade union membership which might improve their own labour conditions.

Since work is the key means for the improvement of people's welfare, skill development and receipt of recognition, having the freedom to attain meaningful work is not only of interest to those who are obliged to work to cover their basic needs, but for all human beings. When labour markets overburden people with tedious work it raises an issue of justice, especially when workers have no other option than to accept such work, there are insufficient opportunities to improve working conditions and some groups are involuntarily overrepresented in such work (Gomberg 2017).

\section{What characterizes meaningful work?}

Whilst the idea of meaningful work has some prominence in political thought, international organizations have preferred to fight labour injustices through the use of the concept of "decent work". Work can be considered decent when people freely enter a labour contract, there is at least some job security and bargaining relations are equitable (Deranty and MacMillan 2012, 387-91). The strength of this concept largely consists in focussing on violations of negative freedoms and thus fighting major harms such as modern-day slavery, extensive exploitation, unjustifiable exposure to hazards such as fire and poisonous chemicals, sexual harassment and child labour. Unfortunately, the concept of "decent work" as a work assessment tool generally lacks consideration of the content of work so I will therefore rely on the more demanding concept of "meaningful work".

So what exactly makes work meaningful? It will not come as a surprise that this question has attracted the attention of scholars from a wide array of disciplines, leading to diverse answers. One of the main problems in defining meaningful work is that the factors that give "meaningfulness" to work are agent-relative (Walsh 1994; Hasan 2015, 481-2; Veltman 2016, 105-141). Many attempts to define "meaningful work" in a single sentence are of little use for our analysis, as they tend to explain the 
concept of "meaningful work" by referring to closely-related adjectives such as work that is fulfilling, valuable, worthwhile, purposeful or significant (Lepisto and Pratt 2017, 102). Once the concept is discussed in more detail, we can observe three major, partly-overlapping approaches to explain what makes work meaningful: (1) by referring to a list of facilitators or attributes that improve the work experience, (2) by identifying an element that transcends the work experience, and (3) when work is perceived as a calling. Let us briefly introduce these perspectives.

(1) List of characteristics. One attempt to define what makes work meaningful is to refer to a list of attributes. For example, work is much more likely to be experienced as meaningful when a sufficient number of the following elements, among others, are present beyond a minimum threshold (Schwartz, 1982; Bowie 1998, 1087): fair wages, opportunities to develop and improve capabilities, non-redundancy, positive contribution to society, social recognition (especially that work is recognized as such), meaningful social interactions, sources of inspiration, balance between work and leisure, having a say on how the assigned tasks are to be done, having a democratic say on the company's policies, being trusted in one's competence, and career ladders. Moreover, for a job to be considered meaningful, such characteristics need be essential, not merely incidental (Walsh 1994, 246). For example, having cheerful colleagues at an assembly line job certainly improves the experience of work, but this is not an essential characteristic of assembly line work, it is just a fortuitous circumstance one may encounter in an assembly line job (idem, 245). Generally, these listed attributes are sought at work to facilitate self-realization, consequently increasing the odds that work is experienced as meaningful.

(2) Transcendental element. A job may have the above traits, but lack a very classical understanding of meaningfulness, which is to contribute to a cause that goes beyond the workplace (cf. Gomberg 2007, 66-69). Subject to this understanding, work becomes meaningful when a certain element transcends the worker-employer relation (Veltman 2016, 115-135), for example by participating in the advancement of science, conserving cultural heritage, assisting people in need, protecting wildlife, or honouring any religious or spiritual commitments. Moreover, people need to be able to see the purpose of their work. As long as people do not or cannot see a purpose in what they are doing it is difficult for them to perceive what they are doing as truly meaningful. Purposeless work can be extremely frustrating or even torturous (Veltman 2016, 119-20).

(3) Work as a calling. The perception of fulfilling a special calling or vocation through work is another strong source of meaning. Callings can have a spiritual source or stay completely secular (Steger 2017, 63-66). People may perceive having a unique talent, character or ability, or being in a particular position of advantage as a calling. An awareness of being in a unique position to perform a socially necessary task can have an inspiring effect. For instance, if someone has the capacity to retain a strong analytic capacity while investigating horrendous crime scenes, the person may interpret this skill together with the huge social importance of criminal investigation as a special source of meaning. 
In contrast to meaningful work we have tedious work. Work does not have to incorporate the above qualities to be regarded as meaningful; however, the absence or insufficient provision of these traits reduces the quality of the work. Work that is characterized by a broad, ongoing lack of the above traits, a lack which falls below a certain threshold, can be considered tedious. The effect of tedious work on workers will depend on the intensity and amount of time they are involved in such work. The community in which one is embedded also influences the meaning of a job, as it affects the social recognition of work. For example, a low-paid job, even when subjectively perceived as meaningful, will receive low social recognition in a community which links high salaries with success. Similarly, it is difficult to perceive a work arrangement as fair when earning less than colleagues whilst doing the same or a more difficult job and this will ultimately affect the subjective perception of the work (cf. Narisada 2017).

A criticism of the current market economy is that it insufficiently stimulates people to work effectively (Lane 1991, 238-40). Work has to be stimulating so that workers feel sufficiently challenged and hence motivated to explore their potential. If, however, work consumes an overwhelming amount of energy and time, it becomes the main source of meaning in people's lives. People who concentrate all their raison d'être in a single element are at much greater risk of losing the sense of purpose in their lives (Veltman 2016, 12-13); even the thought of losing this source may cause fear and anxiety. Whilst the need to find meaning at work will vary depending on the opportunities people have in finding sources of purpose outside of work, securing a sufficient degree of meaningfulness at work remains important since most people are bound to the labour market in order to secure their basic needs.

It is widely debated whether we should rely on an objective or subjective evaluation of the quality of work (Hsieh 2009, 406). Traditionally we can observe a stronger emphasis on the subjective perception of work; in particular, those authors who explore the importance of appreciating spiritual values which encourage personal growth and the gaining of a sense of self have set a strong emphasis on the subjective perception of the quality of work (Lips-Wiersma and Morris 2009, 492-93). Over the last three decades academic philosophers in particular, those who are most familiar with empirical analyses of the problem of adaptive preferences, that is the tendency to only focus on goals that one could reasonably reach under one's circumstances (Sen 2009, 282-83), have underlined the importance of taking into consideration both subjective and objective assessments of the quality of work. People suffering from poverty or discrimination regularly fail to recognize the labour injustices they experience due to their low expectations. Others take the existence of certain barriers, such as international borders, discrimination or exorbitant training fees as inescapable limitations in life which one should learn to accept.

Due to these problems, work should be subjectively felt as fulfilling and objectively perceived as a positive interaction or contribution to something beyond the worker in order to be truly considered meaningful (cf. Wolf 2010, 85-86; Yeoman 2014, 245-46). Because of the vast amount of time apportioned to labour from people's lives, work becomes a central vehicle to promote the development of capabilities and achieve recognition among peers and within one's social circles (cf. Elster 1986; 
Timmermann \& Félix 2015; Schweiger 2013). As a central and necessary component of life it becomes extremely difficult to flourish when continuously engaged in demeaning or menial work (Shiffrin 2003, 1668-69; Veltman 2016, 29). Since continuous engagement in tedious work can be a major hindrance to pursuing one's ideal of the good life and strongly affects the skills one develops, in the next section we shall examine how the idea of contributive justice could be used to advocate an improvement in the quality of work.

\section{What is contributive justice and what does it require?}

Before discussing the different demands of the concept of contributive justice we should ask ourselves why we should add one more category of social justice to our already well-developed bundle of theories of justice.

In today's society, strident demands are being voiced to render the benefits of meaningful work more widely available and attainable (Walsh 1994). Yet people who are obliged to work to cover their basic needs in a world where unemployment and underemployment are abundant have little bargaining power to improve their quality of work (Gilabert forthcoming). The fact that people voluntarily consent to labour contracts does not imply that they also consent to the background conditions under which such labour contracts are signed (Sturn 2009, 82-83). To address the demand for meaningful work we need a normative framework that will allow us to justify or reject specific aspects of work, unfair work divisions and certain barriers to employment. Among the main hurdles which must be cleared in order for people to attain meaningful work we can observe:

(i) Insufficient availability of meaningful work

(ii) Lack of access to training

(iii) The nature of work requiring certain personal attributes

(iv) The customary expectation of certain personal characteristics

(v) Restrictive migration laws

(vi) Institutional corruption

(vii)Discrimination

In addition, we can observe a number of regulations and customs that result in children from underprivileged or migrant households facing enormous difficulty getting better jobs than their parents. Some teachers discourage students from migrant backgrounds from continuing down the educational path that will allow them to go to university because of the false believe that speaking a foreign language at home will make it more difficult for them to understand the course contents. Countries that link school budgets to neighbourhood property taxes create a situation in which the schools from poorer neighbourhoods provide a far worse education than schools from areas that can collect higher taxes (Gomberg 2007, 30-34). 
The most rudimentary framework for defending access to meaningful work is restorative justice, allied with one of its goals, that is, the fight against discrimination. Injustices committed in the recent or distant past towards a group of people can have negative effects on the equality of opportunity for this group or their descendants (Espindola and Vaca 2014, 229). As a strategy to counter such effects one could argue for additional opportunities for people who have been historically disadvantaged (e.g. affirmative action) in order to formally acknowledge that others have received an unfair head start (Bascara 2016, 35-36). There are clear limitations to this approach. For a start, formal equality of opportunity is limited to the public sphere; choices people make in their spare time or within personal circles are generally not subject to the sphere of application of this ideal (Arneson 2015). Yet within the private or semi-private sphere we can observe substantial informal training that can give certain social groups significant advantages in attaining meaningful work. Parents have an enormous effect on the future career chances of their children through acting as role models, mentors and providers (Calder 2016, 133; Gomberg 2010). Further, there is a blurred boundary between what can be considered discrimination and the failure to render sufficiently accessible certain opportunities or means of production. Lastly, it is much more difficult to successfully include in collaborative projects people from outside a privileged community unless a considerable number of people commit to their training and mentoring, ideally by moving to underserved areas.

Distributive justice is generally concerned about how to distribute that what is already in existence or that what can be reasonably expected to exist, and only indirectly with bringing goods into existence. As a practical premise, for goods to be distributed fairly, they need to be divisible, distinguishable and transferable. The first limitation of this approach is that in order to distribute meaningful work, we have to be able to draw a fairly good distinction between work that is generally considered as meaningful and work that is tedious. Yet as we saw in the earlier section the subjectdependency of meaningfulness makes it impossible to successfully distribute meaningful work. ${ }^{1}$ Moreover, a number of jobs cannot be effectively divided and transferred, as they require specific commitments and training.

However, what can be distributed more easily are resources to allow people to access meaningful work, i.e. by making training options more readily accessible. Resources can be distributed to secure sufficient training possibilities for all group members, so that each person has a fair chance of attaining meaningful work. We may think of financing primary, secondary and tertiary education, worker redeployment measures and social reintegration programs for criminal offenders. However, the accessibility of training is no guarantee of its quality and a committed teacher can secure many more opportunities for her students than her job description requires. While formal training is a requirement

\footnotetext{
1 Adrian Walsh $(1994,248)$ concludes that "meaningful work (i.e., eudaimonian activity in the workplace) is a legitimate distributive good, which should be included alongside other distributive goods such as wealth, education, leisure goods, and income." Yet while we may be able to identify jobs that in their job description offer opportunities to exercise and develop skills that demand engagement with theory, in practice we can only distribute such jobs within a small group provided all commit to do a fair share of tedious tasks as well. At a global level, the task of distributing meaningful work fairly becomes unfeasible. This type of practical impediment pushes the distribution of meaningful work beyond the realm of what can be addressed through principles of distributive justice (cf. Lamont and Favor 2013).
} 
for a wide array of highly valued jobs, the power that the informal element within training has in securing certain jobs should not be underestimated. On its own, distributive justice is unlikely to create a sufficient commitment within professional trainers to develop people's capabilities to their full potential.

Resources to improve the work experience can also be distributed, such as improving infrastructure, providing tools and equipment, adequate remuneration, labour rights and support staff. Let us consider police work. A police officer who works in a country that channels an adequate budget into law enforcement is more likely to have received adequate training. This will have given her additional skills to prevent a situation from escalating into violence, thereby avoiding risks and maintaining good relations with local inhabitants - two factors which improve the work experience. In addition, a country that values highly meaningful work may opt democratically for social policies that maximize the availability of work that typifies such characteristics, for example by financing research and cultural institutes. On an international level, we can observe an additional complication. There are huge variations in how countries spend their budgets in education, science and technology, arts and humanities (cf. Timmermann \& Belt 2012; Timmermann 2014). It will require a separate examination to identify the extent to which countries need to include people from other democratic nations in the distribution of meaningful work they have decided to create.

There are some clear limits to the distributive justice approach: the provision of meaningful work requires not only redistribution measures to counter the hoarding of meaningful work by particular groups but also measures to make such types of work more widely available and accessible, as well as measures that go beyond the distribution of resources, so that people are able to contribute, without discrimination, to society. In practice both theories are intertwined (Gomberg 2007, 151-52). A theory of contributive justice is crucial to the justification of the above distributive policies. Whilst distributive justice may help to justify the mechanism for distribution, contributive justice argues why goods such as educational resources and resources to improve the experience of work, e.g. to provide adequate remuneration and staffing, have to be distributed. Even if we decide to interpret distributive justice in a very broad sense, we continue to find some major limitations. While distributing resources may secure time and material resources to allow people to engage in meaningful activities, contributive justice seeks a social organisation that encourages people to engage in such activities, something well beyond the scope of distributive justice. Moreover, meaningful work as currently conceived is a good in limited supply. If competition is used as the main mechanism for distribution, existing social inequalities will lead to an unjust distribution. The aim of contributive justice is different as it seeks to change the perception of what makes life good by focussing on what we can contribute to society instead of what we can receive from society. While the opportunities to contribute to society can potentially be made unlimited, the goods we can receive from society will always be in limited supply. Lastly, some factors that can add meaning to work, such as receiving esteem or cultivating successful relationships, are not distributive goods. These goods are contributive goods in the sense that people can gain access to these goods by contributing to society.

Commutative justice helps us to defend fair remuneration for work and can be generally understood in such a way that it does not exclude people outside one's community. Fair remuneration 
may to a certain degree improve the quality of work and provides the means to pursue meaningful activities outside of work. Yet here we should not ignore the fact that work, under current labour structures, takes a massive toll on people's time and energy (Hardwig 2015). This limits the opportunities to undertake meaningful spare-time activities. Further, securing fair wages to give people money and time to find meaningful activities outside of work is a different strategy for the improvement of social welfare than that sought by contributive justice. I shall return to this point at a later stage.

To address our goal of making meaningful work more widely available and attainable worldwide, the capabilities approach offers a far more complete perspective. The capabilities approach aims at securing opportunities to achieve that which people have good reason to value being or doing (Robeyns 2011). Being able to obtain meaningful work would be something capability theorists would endorse (Sayer 2012), as work is a central vehicle for the development of capabilities (Veltman 2016, 2). Achieving this goal would require a social mandate to redesign workplaces to ensure greater participation in productive and creative endeavours. It would also require the extensive availability of training opportunities and social policies that aim to create new, meaningful jobs. However, the capabilities approach as a liberal theory has certain limitations regarding how far it can demand individuals to commit to the cause of promoting meaningful work for others. Whilst most ideas of social justice condemn discrimination, few would encourage a social mandate to embrace diversity and fewer still to address an obligation to engage in a fair sharing of tedious tasks.

These shortcomings, allied to the importance of meaningful work, call for a broader and more interlinked normative framework to assess and restructure workplaces. Unfortunately much of contemporary political philosophy has suffered a prolonged standstill in providing new arguments for the wider provision of meaningful work. Much of the Rawlsian tradition argues from the ideal economic scenario in which competition for a scarce resource - meaningful work - leads to a situation in which employers have to offer higher wages to motivate people to do less interesting (or tedious) jobs. The argument claims that people will pursue meaningful work for a lower salary rather than tedious work due to the intrinsic motivation that meaningful jobs offer, and markets, not government interventions, are the most effective distribution mechanism (cf. Nozick 1974, 246-50). ${ }^{2}$ However, empirical evidence does not back this reasoning: skilled workers are generally in a much better position to bargain for better working conditions as employers are the losers when such employees leave the company (cf. Keat 2009, 129). Marketable skills that are scarce are much more likely to be adequately remunerated (Dietsch 2008, 98). New starting positions are needed: this is where the idea of contributive justice may come in handy. Let us briefly review the short history of the concept.

The concept of "contributive justice" regained prominence in moral theology during an episcopal conference in the mid-1980s (United States Catholic Bishops 1997, §71). Catholic moral theologians criticized the direction in which industry was going, reducing workers' opportunities to dedicate an adequate amount of time to family life, limiting opportunities to positively contribute to social welfare and creating a competitiveness that destroyed good social relationships (idem, §1-5).

\footnotetext{
${ }^{2}$ See Yeoman $(2014,237)$ for a discussion, primarily questioning the real freedom people have to choose the work they will do in the labour market.
} 
According to the bishops this direction failed to provide the grounds for contributive justice; in their words, "social justice implies that persons have an obligation to be active and productive participants in the life of society and that society has a duty to enable them to participate in this way" (idem, §71). This understanding of contributive justice has two dimensions. First, people have an obligation to contribute to society. Such an obligation is rooted in a Catholic doctrine that is bound to a specific ideal of the common good, one which stresses the importance of traditional family life, of being a good neighbour and of contributing positively to the well-being of one's community (Murnion 1989, 848). Central to this is the principle that people should have the opportunity to contribute to the well-being of society, in terms of a right to work, which is not only a right but also an obligation for able-bodied people (Tablan 2015, 294-96; Sison et al. 2016). Yet we should not interpret this obligation as being grounded in Utilitarian reasoning - work that contributes to human welfare and allows workers to live in dignity and in harmony with family and community life is a good in itself and our ability to work characterises us as human beings (Tablan 2015, 300). Second, contributive justice requires the establishment of social structures that allow people to make a positive contribution to society and a social environment that incorporates such contributions into the overall system without discrimination on the basis of gender, race or other arbitrary standards (United States Catholic Bishops 1997, §73). In their analysis of United States economic life, the bishops were not only concerned about the number of people prevented from developing their talents to the full, but specifically condemned poverty and unemployment being so concentrated among minorities (idem, §14-5).

Following the turn of the millennium, the idea of contributive justice has been further elaborated and secularized to address a wider audience and also other types of circumstance. Within this new wave we can discern two perspectives. The first group, writing from an information science perspective, uses the idea of contributive justice to highlight the missed opportunities, loss of cognitive diversity and injustices committed in failures to provide sufficient access to knowledge and scientific infrastructure. Access would allow people to participate in scientific and cultural advancement and contribute their share of knowledge in the furtherance of such progress (Britz and Lipinski 2001, 24142; Britz 2008, 220-21; Britz and Lor 2004, 1178-80). The second group, whose main representatives are Paul Gomberg and Andrew Sayer, set a strong emphasis on condemning social structures that perpetuate the disadvantages certain social groups have in contributing to society. These two authors condemn the lack of opportunities to contribute to society not so much for the inefficiencies it causes for scientific and technological advancement, but for the effect such division of labour has on people and their social relations. Gomberg in particular has criticized competitive opportunity for never leading to equality and for its role in perpetuating past injustices, particularly regarding racial discrimination (Gomberg 2007). Sayer has shown that a similar mechanism applies to the perpetuation of class privileges and disadvantages (Sayer 2009). For these authors, justice demands that each worker take a fair share of tedious tasks so that underprivileged groups of people do not end up being overburdened with low-quality jobs.

Having taken these perspectives in consideration, we can identify six elements which can be listed as the key demands of contributive justice: 
(1) Opportunities to participate

(2) Opportunities to develop skills

(3) Opportunities to learn to be productive

(4) Fair evaluation of inputs (fair competition of ideas)

(5) Duty to do one's share according to one's capacities

(6) Meaningful work and tedious tasks should be distributed more evenly

There is still no agreement regarding the threshold to which these demands should be satisfied. The newer interpretations of the concept are also more open to Utilitarian reasoning. As is common with many concepts in philosophy we can expect a number of revisions and additions to this preliminary list of demands.

To address contributive justice, widespread individual and collective action is needed. The authors who have coined the renewed concept of contributive justice did not assign obligations to specific groups of people or governments; rather, they opted to show which types of work structures, capacity-building efforts, scientific practices, innovation incentive systems, educational policies and interpersonal relations limit and foment the possibility of progressively achieving the six elements encompassing contributive justice. Let us take a closer look at the six demands thus far attributed to the concept and analyse how they can be complemented by additional insights from contemporary political philosophy.

\section{Opportunities to participate}

As workplaces are a key vehicle for self-realization and overwhelmingly shape the contribution people make to society, it is increasingly crucial to allow wider participation in these or similar environments. The number of people seeking to improve their work situation reveals that there is a significant demand for opportunities to contribute more positively and effectively to society. One of the central demands of contributive justice is to expand such opportunities, both for people who are obliged to work to cover their basic needs and for those who are interested in the non-pecuniary advantages of meaningful work. To address this demand, policy efforts should concentrate on providing sustainable meaningful work and company managers should not sacrifice meaningful jobs for minor reasons when restructuring workplaces.

The way production systems and whole industries are structured affects the availability and quality of labour. Some industries have separated manufacturing sites from research facilities, often to other parts of the world, drawing a firm distinction between those who conceive and those who assemble products. The structure of workplaces has a direct effect on who is able to participate and how participation will appear (Taka and Foglia 1994; Sayer 1989). For example, an increase in hours in the standard working week has an enormous effect on workers' social and family life (Valente and Berry 2016). In some jobs it is not possible to work less than the average colleague; in others it is but people cannot stay competitive in the labour market if they opt to do so. Here we should distinguish cases where flexibility in working hours is limited due to the nature of work or limited by the way the 
workplace is structured. Scientists studying biological processes have to adapt their working hours to the behaviour of their object of study. Polar researchers and soldiers in conflict areas work in environments that are incompatible with most types of family life. However, in many cases it is society and not the nature of work that sets the incentives that motivate employers to opt for employees who work longer hours. For example, in academia we have citation rankings that do not distinguish between researchers working part-time or over-time. Tax and labour laws can also influence a manager's decisions to hire an extra employee or to incentivize current employees to work for longer hours. Some regulations and alternative rating systems are needed to help people combine leisure and family life with work. Workplaces gain intellectually and socially when at least some workers have broad experience from beyond the working environment.

A further element limiting participation appears when specialized jobs require prolonged postschool training, either through long apprenticeship or tertiary education. According to this notion of justice the opportunity to participate should be available to people from all backgrounds: household income, birthplace, or any other form of work-irrelevant discrimination should not play a role. ${ }^{3}$ Whilst limited resources force selections, aspirers should be able to improve their odds primarily through their own efforts. Careers in which people retain a student or apprentice status for a prolonged time despite working independently and not receiving a significant amount of training (other than self-training) or mentorship - such as academia, international organizations and NGOs (which ironically embrace the principle of equality of opportunity) plus, increasingly, industry - limit participation possibilities and reduce the quality of work when the converse approach is inadequately remunerated and not compelled by labour rights. ${ }^{4}$

Access to fundamental infrastructure is essential to a wide range of specialized activities. Underfinanced or non-existent cultural and scientific infrastructures are among the greatest factors limiting wider participation. Governments, civil society and individuals should undertake a larger effort to make this material infrastructure available and accessible in rural and urban areas. Notably, one of the key non-food related demands in food sovereignty advocacy is the improvement of rural infrastructure (Via Campesina 1996). Physical access should also be safe from avoidable hazards and sexual harassment, and adapted, as far as feasible, to the needs of people with disabilities. Here it should also be noted that restrictive migration laws are hindering wider international inclusion in scientific and cultural projects (Shaheed 2012, 12). Increasingly, there is a need also to access intangible infrastructure. Patents, copyright, plant breeders' rights and material transfer agreements are all instruments used by proprietary science practices that limit opportunities to fully participate in scientific and cultural life (cf. Shaver 2010; Timmermann 2014). Access to scientific literature, genetic resources, materials that have become industry standards and freedom to follow certain processes affect people's opportunities to participate in intellectual life. Most companies do not open up access (e.g. through humanitarian licences) to proprietary scientific objects even for those who are clearly unable to pay (e.g. for agriculture, see Louwaars 2007, 129). Hindering people's participation in productive

\footnotetext{
${ }^{3}$ For strong scepticism that the principle of equality of opportunity shall ever be more than a mere ideal, see Mijs (2016).

${ }^{4}$ For an excellent discussion of the job market for academic philosophy and its effect on diversity and well-being, see Behrensen and Kaliarntra (2017).
} 
enterprises limits human flourishing not only directly but also indirectly, by diminishing the potential intellectual input entering the scientific, cultural and economic domain, thus inhibiting cognitive diversity.

Lastly, as has been mentioned countless times over recent decades, extreme poverty and discrimination are the most severe limitations upon human flourishing (Pogge 2008, 33-57). Hunger, disease, physical and psychological threats and violence, inadequate shelter and difficult access to safe water and sanitation systems are by far the greatest impediments to wider social inclusion and the use and development of creativity. People who are hungry spend almost all of their time thinking about only one thing: food (J. Ziegler 2011, 68). Basic needs have to be secured to allow people to participate in society (Gomberg 2007, 160).

\section{Opportunities to develop skills}

Skills are valued both as a means and in themselves. Labour markets are dynamic and thus require workers to constantly develop their abilities, to become familiar with the cutting edge of their trade or profession and to gain increasing proficiency with new technologies (Tight 1998). Competition increases the need to adapt to the evolution of professional requirements. Acquiring and developing skills is crucial to not only for acquiring but also for retaining employment.

Independent of any developments in the labour market, the possession of skills is also important for building up self-esteem and the enjoyment of a fulfilling social life. A person's profession, which entails a required set of qualifications and skills, plays a crucial role in the development of an identity (Herzog 2011). Workers who are treated as unskilled replaceable assets tend to perceive work as undignifying (Lucas 2015, 635-37). Pursuing complex tasks is also something humans value on their own. We may think of Rawls' Aristotelian Principle, arguing that people enjoy exercising their innate and acquired abilities, an enjoyment that increases with the complexity of the activity and awareness of one's virtuosity (Rawls 1999, 372-80; R. Taylor 2004, 338-40). Achieving proficiency in an area is something many consider of central importance in their image of a good life (Gomberg 2010, 8-9).

In addition, many skills can be extrapolated for uses beyond the workplace. To take an example, good communication skills acquired at work become great assets for people interested in becoming involved in wider social circles. Skills acquired at work, together with continuing education, empower people with the necessary capabilities to enhance their civic participation (cf. Terzi 2007, 3132; Schaff 2012, 390) and to observe whether national policies are in line with international goals. Consequently, those engaged in meaningful work gain additional non-monetary advantages over those who are continuously involved in tedious tasks.

However, it is important that skills, or more widely capabilities, are not only learned, but that people have regular opportunities to make use of them (Sayer 2012, 583-84). The joys of mastering a discipline or craft are principally felt when performing or completing work. Being deprived of the opportunity to exercise one's craft could be perceived as even more frustrating than not mastering anything at all. Similarly, continuously doing work for which one is overqualified reduces the positive 
experience of work (Lucas 2015, 633). Therefore there should be some positive correlation between the kind of activities people can reasonably pursue in the labour markets and the overall level of education and skills needed as citizens to critically assess political, environmental and technological hazards and opportunities. Clearly this is a major challenge considering the huge discrepancies in education and training levels between and within countries in a world where environmental hazards ignore national borders and technologies are being exported all over the world.

\section{Opportunities to learn to be productive}

Arguably, one could also count being productive as a skill in itself. However, with competitive global markets and the vast differences in productive capacity conferred by science, technology, peer group and education, it is increasingly important to treat "being productive" as a separate trait, as these productivity-enhancing assets are very unevenly distributed - something also recognized by human rights advocates (Sarkin and Koenig 2011, 9). Being much less productive than others doing the same type of work can be an impediment or a major disincentive to contribute. Relatively low productivity is also socially unsustainable, as individuals have to work for many more hours for the same or lesser results. A competitive market does not generally value effort when setting prices on identical or very similar objects. Having to work for a greater number of hours to produce an object which competitors make in much less time has a direct effect upon the quality of work, as remuneration and recognition for one's efforts fall short of one's expectations.

As mentioned, many professions require material goods and an infrastructure. Taking contributive justice seriously would require some redistribution of resources in order to render competitive the material and social situation, that is, the means of production and the means to be productive. Here we can either secure unhindered access to the material as well as immaterial means of production (e.g. libraries, shared office spaces) (Frischmann 2012) or transfer property rights in order for people to be able to secure their livelihoods by their own means (cf. Claassen 2015, 231-32).

On a global level, learning to be productive should not be mindlessly equated with maximizing production without considering negative externalities. Many production systems in the Global South are very efficient, particularly sustainable agriculture, if total output and environmental impact are considered (Timmermann \& Félix 2015). To judge the efficiency of a production system we need to assess alongside productivity the quality of the work involved and its environmental impact. In a highly populated world a production system which ignores the social dimension causes civil unrest and neglecting the environmental dimension is having major negative effects on health.

\section{Fair evaluation of inputs (or fair competition of ideas)}

To sustain a willingness to contribute to society, it is vital that people are sure that their contributions will be fairly evaluated. People will tend to see participation in scientific and cultural endeavours as pointless if their contributions, regardless of merit, are generally ignored or downplayed. The "ideas market" should therefore be subject to fair competition to ensure the widest and most enthusiastic 
participation (R. Ziegler 2011). However, establishing a level playing field is a very difficult task: people with fame, power, media control or priority access to information and technology have ample opportunity to rig competition in their favour (Sparrow and Goodin 2001, 52-53).

Favouring ideas that come from a preferred ethnic group, gender, culture or race can amount to a massive disincentive, as it is a form of discrimination. Discrimination can have multiple faces. Sometimes the person behind an idea is taken less seriously or ignored; in other cases this is the fate of content depicted in certain ways (Fricker 2007). We have to add to this category the potential for selfdiscrimination by people who identify with an underrepresented group (C. Taylor 1994, 25-26; Kumar and Santoro, forthcoming). To take an example, a society that belittles women's opinions in certain fields may discourage women from criticising male counterparts. Or contrarily, it may over-incentivize women to prove their skills at a much higher level than expected at a given career stage, causing outbreaks of overwork and thus impeding a work/life balance.

It is a matter of debate the extent to which a fair competition of ideas entails levelling the playing field. It could be argued that those from socially disadvantaged groups or those with certain types of disabilities should be given extra tutoring or material assistance to reduce the additional burdens they face and this remains an unresolved issue in the equality of opportunity debate (Moellendorf 2006, 304-6).

Sustaining fair competition is expensive and requires the redirection of resources. Evaluating ideas is time-consuming and expense can be spared by continuing to rely on sources that have proven effective in the past. Nonetheless, broadening the range of idea sources increases originality and this may incentivise the evaluation of ideas coming from all around the world. Nonetheless, when incorporating ideas from indigenous communities and underrepresented historical sources attention has to be paid to avoid cases of biopiracy or plagiarism. Sources should receive due credit (Kelbessa 2013). Special protocols have to be established on how to handle traditional knowledge which may be of great use to the global community but may also negatively affect the traditional communities from which such knowledge originates.

\section{Duty to do one's share according to one's capacities}

More controversial is the suggested obligation to be active in society (Britz and Lipinski 2001, 24142 ), or in an even more demanding version, the duty to do one's share according to one's abilities (Gomberg 2016, 47-49; 2007, 152). Such a contributive justice demand raises a number of controversies (Murnion 1989) and it will be a major challenge to weave this element into a wider theory of justice; (this also continues to be a challenge for the socialist principle "From Each According To Their Abilities, To Each According To Their Needs", see Gilabert 2015). First, humanity through several declarations proudly reserves freedom of speech. People ought to have the liberty to choose in which direction to exercise their freedom to express themselves or not to express at all. Participation, in order to be meaningful, cannot go without self-expression. Second, a duty to contribute according to one's capacities can be seen as a form of conscription. Traditionally, liberal societies only support conscription if a proportional threat to liberty is at stake, such as an invasion by 
an enemy army (Rawls 1999, 334). In addition, in order to police who is contributing according to their capacities and who is not, a government needs to intrude substantially into people's privacy (Otsuka 2008, 446). Third, a disincentive to develop skills may arise if there is a conscripted use of them. As a reaction, people could simply choose to concentrate on areas where their skills would not be so strongly demanded by society (Stanczyk 2012, 160). A researcher who specialized in cosmetic surgery instead of neglected tropical diseases would be saved a lot of trouble if her aim were to make money. Fourth, taking seriously a duty to contribute according to one's capacities leaves open the questions of to what extent and to what degree people are obliged to develop skills. Is someone with a talent for music under an obligation to practice her instrument for 10000 hours in order to become a virtuosa (cf. Sennett 2008, 20)? Do we have a duty to develop skills that are required for addressing injustices (Parr 2015; Gomberg 2007, 77, 152)? Or should any acquisition of skills beyond primary schooling have a supererogatory character? Depending on how these questions are answered we will have a very different picture of how a just society should look.

Making contributions compulsory will have to be countered by defence of the liberty to pursue idle activities and to concentrate on family and social life. Leisure time is a human right (Universal Declaration of Human Rights, art. 24) that took a huge effort to be universally recognized. Although fixing a standard quota of leisure time is an issue which could be settled by consensus (Claassen 2012, 559), we have an additional difficulty when the potential each person has to contribute varies so strongly depending on their expertise and geographical location. Furthermore, what counts as fair leisure time will be affected by the urgency with which the person's skills are needed (e.g. to fight disease or hunger). Thus consensus is problematic, for we may ponder a doctor's right to enjoy her teatime in a chronically underserved area that exists in a permanent state of emergency.

Perhaps an obligation to contribute according to one's capacities could be aligned with efforts to limit free-riding. Overly relying on other people's skills without giving back (if capable) can be seen as a form of free-riding. In a society which unavoidably puts us in touch with other people a number of social institutions are needed to guarantee basic securities and freedoms. In this sense, free-riding is not doing one's share when it is our turn (Barry 1982, 229). Placing oneself in a position in which one is unable to help, especially when an eventual need was foreseeable and training possibilities were available, could be perceived as a form of being unwilling to contribute (cf. Wolff 2004, 289) or as violation of the principle of reciprocity (Gilabert 2015, 199-200). However, those unwilling to develop skills could still offer to compensate for their reliance on other people's intellectual services by engaging in a greater share of tedious work. If this group of people had a fair chance to acquire skills and knowledge, it would be problematic in a liberal society to insist upon them developing such skills as long as they were doing their fair share of work.

Despite these objections, a possible line of argument for defence of this obligation is to claim that there is something intrinsically valuable in a highly participative democracy and that cognitive diversity is essential for the advancement of social welfare. For someone's intellectual contribution to be beneficial to society it is essential that she develops skills up to a certain social standard. Here the argument would gain much strength if empirical evidence showed that the participation of inadequately educated, under-skilled people in the economic and political systems caused harm to others (cf. 
Brennan 2011, 722-23). As our world becomes more interconnected it is important that people develop skills to effectively participate in deliberative processes on matters that concern all people in the planet, such as climate change and disease control.

Fortunately, the more people live up to the principles of contributive justice, the less demanding becomes the duty to do one's share according to one's abilities. The more people develop skills and contribute to social welfare, the less likely it will be that we as humanity live in a continuous state of emergency in which extreme poverty, hunger and disease are endemic and thus set an enormous demand on those who have developed urgently-needed skills. Moreover, people who want to make a difference will more likely succeed in receiving additional esteem or in improving social welfare when they engage in areas that are currently underserved (Gomberg 2016, 49).

Meaningful work and tedious tasks should be distributed more evenly

Meaningful work seldom comes without the need to undertake less interesting tasks. There are various maintenance and administrative tasks that need to be done as part of larger projects. We could say that for every meaningful job there is a share of tedious tasks that has to be done as part of the overall process. A more even distribution of meaningful and tedious tasks would require taking on a certain "fair share" of tedious tasks as well (Sayer 2011, 12-16; Gomberg 2016, 50; Gomberg 2007, 75-90). Fortunately, many uninteresting tasks become less tedious when undertaken as part of a more meaningful endeavour, e.g. taking out one's own garbage (Sayer 2009, 10). Contributive justice can only be achieved when more powerful groups do not monopolize meaningful work and leave tedious tasks to weaker groups or group members.

However, there will remain a number of jobs that are generally unattractive but still require skilled specialists. The cleaning of sewers and the disposal of toxic waste are jobs that are critical for human welfare but generally do not figure among people's career dreams. These tasks still require training and are therefore less suitable for sharing among the wider population (Walzer 1983, 165-83).

Taking these issues into consideration, society should continue in its efforts to reduce the number of tedious jobs as well as the tediousness of certain tasks through technological and scientific innovation. Here we should be conscious that many products we consume and use on a daily basis are built with raw materials extracted under appalling labour conditions and often also assembled in highly exploitative work arrangements. To achieve the above ends, inventiveness will have to reduce and eliminate tedious work at all levels of the production chain, as well as in offices and homes.

\section{Should we follow the demands of contributive justice?}

To continue with this exploration, we need consider whether we should support a working environment conducive to the six demands of contributive justice. I divide the main arguments into two parts: 
authors supporting the demands of contributive justice and those questioning the aims of this notion of justice.

Social benefits of addressing contributive justice

Addressing the demands of contributive justice can provide a wide range of social benefits. For brevity I shall discuss only four elements, these being its potential to promote autonomy, personal development, empowerment and productivity.

Work, as mentioned, is the quintessential means for people to secure their livelihood and thus is generally obligatory. The insufficient availability of vacant land forces large numbers of people to offer their labour on the job market. Especially when there is an oversupply of labour, workers are compelled to offer their services under unfavourable conditions (Schaff 2012, 390-91). Such arrangements can be significantly detrimental to the quality of the work. A society that values autonomy should guarantee an institutional order that does not overburden certain social groups involuntarily with menial work (Roessler 2012, 91-93). The fact that work is mandatory to cover subsistence does not imply that any particular division of labour that sufficiently covers such needs is justified. Despite work being a necessity, labour agreements should ideally be framed as if it were voluntary. A fairer distribution of meaningful work improves the odds that people will contribute to society not only because they are obliged to, but because they want to (Gomberg 2016, 44-47). Another benefit of such distribution is that it makes it much more difficult to maintain relations of strict subordination - and subordination not only reduces autonomy but diminishes the quality of work in general (Graeber 2006, 67-69; Hsieh 2009, 398-400). Many tasks demand an ability to work as part of a team, something that requires good social relations for their successful execution.

An environment conducive to personal development has both direct and indirect benefits to individuals and society. The development of capabilities allows people to make better choices by improving their capacity to acquire information as well as having the ability to critically judge the information and the circumstances they encounter. This allows people to make better choices, avoid certain harms and defend themselves against attempts at deception. Furthermore, as shown above, skill development is something people also value in itself.

As each adult needs to work to cover subsistence in most countries of the world, the acquisition of a wider array of skills improves people's chances of having a choice concerning their employment. Having choices reduces dependency and consequently also vulnerability (Anderson 2015, 56-58). In many areas of the world, where the only type of work people can get requires physical strength, those people who cannot compete in this area will be in a position of dependency. If such an environment promotes a male breadwinner model and overburdens women with unpaid care work we also face an issue of gender injustice (Veltman 2016, 160-61). Facilitating the development of skills and promoting a work ethos that stimulates a fairer distribution of meaningful work empowers a much wider range of people.

Lastly, the goods and services work produces can play a considerable part in improving individual, family and social well-being. However jobs differ significantly in their social utility 
(Graeber 2013). Awareness of one's minuscule or negative contribution to social welfare may have considerable effects on self-esteem. True empowerment also requires being productive and here people should have a certain influence on the rate and direction of production. Effort should pay off. This necessitates wider access to the means of production and equality of opportunity to develop the skills required.

\section{What are the conflictive implications of adhering to contributive justice?}

I will concentrate on three major objections to which the concept of contributive justice may give rise: (1) it limits the liberty to enjoy menial work by objectively judging the worth of such work, (2) it favours efforts to supply work instead of abolishing work and (3) it jeopardizes the freedom to abstain from unfair systems.

I will start with the first issue. One of the main criticisms of government involvement in securing human flourishing through meaningful work is the charge of perfectionism. By favouring work as a vehicle for self-realization a particular lifestyle (i.e. finding meaning in work) is given preference over other lifestyles (i.e. minimising work and finding joy outside the workplace).

Further, improving people's chances of attaining meaningful work requires agreement on a common meaningfulness of work scale, giving one valuation precedence over (possible) preferences. At first sight one could set aside this problem by simply stating that work may be considered meaningful when people state subjective satisfaction. There are some problems with this solution. First, some people are difficult or impossible to be rendered happy through their work and often consciously choose to find pleasure in other areas of life, such as childrearing or traveling. A system that insists on fulfilling people's lives through work will fail if it does not take into account a wider dimension, e.g. well-being during leisure time - and even then, in some exceptional cases such a system will still fail altogether cf. (Veltman 2016, 10-14). Second, people tend to aspire only to what they can reasonably achieve and thus have lower expectations when accustomed to deprivation (on adaptive preferences, see Dieterlen 2003, 72-75; Sen 2009, 282-83). Career aspirations reflect ties to initial deprivations rather than free choice (Gomberg 2007, 28-43).

Questioning the authenticity of self-reported labour satisfaction brings in the huge problem of elaborating a scale that measures the quality of work objectively, with the unavoidable consequences that one person's work may be objectively perceived as menial, whilst subjectively highly regarded, or the other way around. We may always question the appropriateness of the yardstick by which we measure the meaningfulness of work (Arnold 2012, 115-16; Burchell et al. 2014, 464-65), as the extent of having to take into account work satisfaction to improve quality of life is strongly dependent upon the material objects to which people aspire and are socially expected to have (on "to appear in public without shame", see Sen 2001, 72-74), requiring working hours to be produced; one need also consider the amount of satisfaction people can reasonably achieve during leisure time (Gilabert 2016, 179). If policies are set to reduce the amount of menial work in order to create meaningful work, people who highly value their occupation may lose their job and be pushed towards objectively highly esteemed 
work that is not subjectively perceived as fulfilling. Some people can gather an enormous amount of well-being doing objectively menial tasks: who are we to prohibit this?

One may also question the necessity of securing meaningful work altogether: an alternative approach would be to guarantee sufficient leisure time to counter-balance monotonous work, thus allowing people to find meaning outside workplaces. A strong version of anti-perfectionism not only criticises preferring one type of work over the other, but questions entirely the provision of meaningful work as vehicle for self-realization. This second objection inculpates contributive justice of spending resources on creating new jobs instead of using those same resources upon measures that will allow the abolition of work, such as automation and the development of artificial intelligence. Instead of insisting on the possibility of supplying meaningful work for all, we could accept the possibility that we can largely abolish human labour and develop theories of distributive justice that will allow the sharing of the benefits of machine labour more widely (cf. Danaher 2017, 44-47). There are two major groups opposing a systematic creation of additional meaningful work opportunities using public funds. The first group, consisting of advocates of an unconditional basic income, start with the premise that society cannot secure full employment (Offe 2009, 50-54). Governments should rather give people an unconditional basic income and allow individuals to decide how to live their lives - seeking further paid employment or living modestly doing what they desire (Van Parijs 1997, 32-35). In many cases artificial job creation demands resources, thus requiring others to spend more time working instead of enjoying their free time, e.g. people working on research have to be sustained by taxing people doing other types of work who would often rather work less and spend that extra time with their families and friends. If a decent standard of well-being can be secured through efforts to abolish human work through technological innovation, contributive justice would have to defend the notion that we should prefer a society in which people pursue meaningful work over one where people do not have to work at all. A second group criticises the perfectionist agenda of a government which involves itself in shaping participatory work environments (cf. Arneson 1987, 524-27; later making some concessions in Arneson 2009, 148). Governments should not value one lifestyle over another and thus should not interfere with the structure of workplaces to force a wider accessibility of meaningful work. People should be free to pursue less demanding paid work if they prefer to focus their energy upon enjoying their spare time. For example, doing intensive or exhausting work for long hours may reduce one's attentiveness as a parent.

A third criticism of contributive justice questions the compatibility of this notion of justice with conscientious objection and the liberty to boycott unfair systems. Demanding wider participation is at odds with respecting people's liberty to object to a lifestyle or social order by reducing their cooperation to a minimum. Throughout history people have made use of their liberty to avoid cooperating with partners they identify as unjust, even in cases in which it comes at substantial personal or group cost (Ooms 2010). This is a deeply rooted trait which we share with other species (Dodds 2005, 417-18), and as such, it is crucial to leave sufficient room for such an urge within a social system. 


\section{Can we live with these implications?}

Perhaps the most prominent accusation against any top-down demand to restructure workplaces in order to add meaningfulness to work is the charge of perfectionism, or in general terms, a violation of the principle indicating that the state should not interfere with the liberty of workers to opt for undemanding labour, whatever their personal reasons for such a choice (Arneson 1987, 526-27). However, the current structure of workplaces is not the sum of individual well-informed choices. Workplaces are structured following up-to-date or often even out-dated business management models that aim to secure profits which are essential for the long-term survival of the company, or in less benign cases, simply to maintain power relations that allow company managers to exert control over their employees (Spencer 2013, 588-89). Further, the absence of enforceable universal labour laws incentivizes poorer countries to offer a cheaper and cheaper workforce as an essential element in a competition to attract foreign capital by offering the lowest manufacturing costs (cf. Young 2004, 36970; Snyder 2010, 207; Gilabert 2016, 176). We can observe this so-called race to the bottom not only between countries, but also increasingly within countries (Sklair 2016, 330). From this perspective, an appeal to maintain the current integrity of workplaces loses a great deal of ground and we have to be cautious in granting a group of workers who enjoy the current status quo anything resembling a veto over changes to existing work structures (Spencer 2013, 593). Whilst non-interference in work structures leads to greater autonomy for the few, it allows significant abuses of power and thus jeopardizes self-determination for the many (Kates 2015, 192-95). From a moral perspective, it is important to realize that vast inequalities in the distribution of meaningful work are avoidable: workplaces can be redesigned to allow a wider provision of interesting, demanding and autonomous work (Arnold 2012, 107-8; Gomberg 2007, 163-65). Meaningful work, as mentioned, is not only the central vehicle for most people to develop skills and gain recognition, but without meaningful work it becomes much more difficult to live a fulfilling life under the current standard working week.

Further, analysing this problem from a global perspective urges us to acknowledge some very hard facts. While there are a number of workers who greatly enjoy their low-skilled jobs, these workers, as well as almost everyone else, on a regular basis consume products made by other people who do not enjoy their low-skilled jobs at all - indeed, quite the contrary. Labour conditions in "sweat shops", in a large part of the developing world's mining industry and in commercial agriculture are having a terrible effect on the workers' physical and mental health. At the same time, we can also find a number of jobs that require a variety of skills but are still considered meaningless due to their low or zero contribution to social welfare. Many of these workers are submerged in consumerism and thus increase the demand for products made in sweatshops (Hardwig 2015, 282-83). Furthermore, here we should also note that we could significantly improve labour conditions without major changes to our lifestyles.

As far as the argument goes that resources should be rather spent upon the abolition of work than the artificial creation of meaningful work, we can say that at least for the current generations work will still be a necessity. Extreme inequality and the cheap availability of unqualified labour around the world do not stimulate research and technological development to reduce our global dependency upon 
tedious work in every field. In any case, efforts to abolish work are not at odds with the premises of contributive justice. Aims to eliminate tedious work are generally welcomed as this type of work consists more in a burden than an opportunity. Indeed, one of the challenges of contributive justice is to motivate people to take their fair share of tedious work so that some groups (or even entire regions) will not be overburdened with carrying out menial tasks.

Besides the ecological footprint of today's consumption patterns, a major reason to oppose current manufacturing practices is the unacceptably low labour standards of a great number of industries. People should have some liberty not to be obliged to contribute to a system they perceive as unjust, especially when they are not enjoying most of the benefits such social structures offer. The wider idea of contributive justice embraces this very criticism regarding labour conditions and aims at changing business management models while not advocating a major disruption of production. However, here we should be cautious, for in shifting the default from "liberty" to "contributing" one places those who deviate from the norm in a much more vulnerable position, especially those who limit their cooperation to a minimum because of a reasonable fear of causing harm.

Perhaps the real strength of the notion of contributive justice is not so much to fight for a society in which people are constantly developing their skills and continuously improving their education, but where we as a society take stronger precautions regarding the long-term mind-numbing nature of some types of work and the way deskilling affects the opportunity to fully and constructively participate in cultural, scientific, economic and political life. The true potential of the concept of contributive justice may rest in becoming a societal aspiration at which people aim, both in their professional and personal lives.

Finally, despite these shortcomings, I hope to have shown that the idea of contributive justice is a concept worthy of further normative analysis, as it could be forged into a fine tool for assessing workplaces, one which probes deeper than the issues of fair transactions and the redistribution of resources.

\section{Acknowledgements}

Acknowledgements: I would like to thank the participants at workshops in Mexico City, Budapest and Campinas, Isabella Trifan, Georges Félix, the journal's editor and the anonymous reviewers for valuable feedback and Michael Pockley also for careful language editing on earlier versions of this article.

\section{Compliance with Ethical Standards:}

Ethical approval: This article does not contain any studies upon humans or animals performed by the authors.

Funding: This study was funded by a post-doctoral fellowship by DGAPA-UNAM and FONDECYT/CONICYT 3170068. 
Conflict of Interest: The author(s) declare that they have no conflict of interest.

\section{References}

Anderson, E. (2015). Equality and freedom in the workplace: recovering republican insights. Social Philosophy and Policy, 31(02), 48-69.

Arneson, R. (1987). Meaningful work and market socialism. Ethics, 97(3), 517-545.

Arneson, R. (2009). Meaningful Work and Market Socialism Revisited. Analyse \& Kritik, 31(1), 139151.

Arneson, R. (2015). Equality of Opportunity. In E. N. Zalta (Ed.), The Stanford Encyclopedia of Philosophy (Summer 2015 Edition) ((Summer 2015 Edition) ed.).

Arnold, S. (2012). The Difference Principle at Work. Journal of Political Philosophy, 20(1), 94-118.

Barry, B. (1982). Humanity and Justice in Global Perspective. Nomos, 24, 219-252.

Bascara, R. (2016). Compatriot partiality and cosmopolitan justice: Can we justify compatriot partiality within the cosmopolitan framework? Etikk i praksis-Nordic Journal of Applied Ethics, 10(2), 27-39.

Behrensen, M., \& Kaliarnta, S. (2017). Sick and Tired: Depression in the Margins of Academic Philosophy. Topoi, 36(2), 355-364.

Bowie, N. E. (1998). A Kantian theory of meaningful work. Journal of Business Ethics, 17(9), 10831092.

Brennan, J. (2011). The right to a competent electorate. The Philosophical Quarterly, 61(245), 700724.

Britz, J. J. (2008). Making the global information society good: A social justice perspective on the ethical dimensions of the global information society. Journal of the Association for Information Science and Technology, 59(7), 1171-1183.

Britz, J. J., \& Lipinski, T. A. (2001). Indigenous knowledge: A moral reflection on current legal concepts of intellectual property. Libri, 51(4), 234-246.

Britz, J. J., \& Lor, P. (2004). A moral reflection on the digitization of Africa's documentary heritage. IFLA journal, 30(3), 216-223.

Burchell, B., Sehnbruch, K., Piasna, A., \& Agloni, N. (2014). The quality of employment and decent work: definitions, methodologies, and ongoing debates. Cambridge Journal of Economics, 38(2), 459-477.

Calder, G. (2016). Family autonomy and class fate. Symposion, 3(2), 131-149.

Claassen, R. (2012). Temporal Autonomy in a Laboring Society. Inquiry, 55(5), 543-562.

Claassen, R. (2015). The Capability to Hold Property. Journal of Human Development and Capabilities, 16(2), 220-236.

Danaher, J. (2016). Will life be worth living in a world without work? Technological Unemployment and the Meaning of Life. Science and engineering ethics, 23(1), 41-64.

Deranty, J. P., \& MacMillan, C. (2012). The ILO's Decent Work initiative: suggestions for an extension of the notion of "decent work". Journal of Social Philosophy, 43(4), 386-405. 
Dieterlen, P. (2003). La pobreza: un estudio filosófico. México, DF: Fondo de Cultura Económica.

Dietsch, P. (2008). Distributive Lessons from Division of Labour. Journal of Moral Philosophy, 5(1), 96-117.

Dodds, W. K. (2005). The Commons, Game Theory and Aspects of Human Nature That May Allow Conservation of Global Resources. Environmental Values, 14, 411-425.

Elster, J. (1986). Self-realization in work and politics: The Marxist conception of the good life. Social Philosophy and Policy, 3(02), 97-126.

Espindola, J., \& Vaca, M. (2014). The Problem of Historical Rectification for Rawlsian Theory. Res Publica, 20(3), 227-243.

Fricker, M. (2007). Epistemic injustice: power and the ethics of knowing. Oxford \& New York: Oxford University Press.

Frischmann, B. M. (2012). Infrastructure: The social value of shared resources. New York: Oxford University Press.

Gheaus, A., \& Herzog, L. (2016). The goods of work (other than money!). Journal of Social Philosophy, 47(1), 70-89.

Gilabert, P. (2015). The Socialist Principle "From Each According To Their Abilities, To Each According To Their Needs". Journal of Social Philosophy, 46(2), 197-225.

Gilabert, P. (2016). Labor human rights and human dignity. Philosophy \& Social Criticism, 42(1), 171199.

Gilabert, P. (forthcoming). Dignity at work. In H. Collins, G. Lester, \& V. Mantouvlou (Eds.), Philosophical Foundations of Labour Law. Oxford: Oxford University Press.

Gomberg, P. (1995). Against Competitive equal opportunity. Journal of Social Philosophy, 26(3), 5973.

Gomberg, P. (2007). How to make opportunity equal. New York: Wiley Blackwell.

Gomberg, P. (2010). Dilemmas of Rawlsian Opportunity. Canadian Journal of Philosophy, 40(1), 124.

Gomberg, P. (2016). Why Distributive Justice Is Impossible but Contributive Justice Would Work. Science \& Society, 80(1), 31-55.

Gomberg, P. (2017). Workers without Rights. Symposion, 4(1), 49-76.

Gourevitch, A. (2016). Quitting work but not the job: Liberty and the right to strike. Perspectives on Politics, 14(02), 307-323.

Graeber, D. (2006). Turning modes of production inside out or, Why capitalism is a transformation of slavery. Critique of Anthropology, 26(1), 61-85.

Graeber, D. (2013). On the phenomenon of bullshit jobs. Strike! Magazine, August, 10-11.

Hardwig, J. (2015). Ownership, Possession, and Consumption: On the Limits of Rational Consumption. Journal of Social Philosophy, 46(3), 281-296.

Hasan, R. (2015). Rawls on meaningful work and freedom. Social Theory and Practice, 41(3), 477504.

Herzog, L. (2011). Wer Sind Wir, Wenn Wir Arbeiten? Soziale Identität Im Markt Bei Smith Und Hegel. Deutsche Zeitschrift Für Philosophie, 59(6), 835-852. 
Hsieh, N. h. (2009). Justice at Work: Arguing for Property-Owning Democracy. Journal of Social Philosophy, 40(3), 397-411.

Kates, M. (2015). The Ethics of Sweatshops and the Limits of Choice. Business Ethics Quarterly, 25(2), 191-212.

Keat, R. (2009). Anti-Perfectionism, market economies and the right to meaningful work. Analyse \& Kritik, 31(1), 121-138.

Kelbessa, W. (2013). Indigenous knowledge and its contribution to biodiversity conservation. International Social Science Journal, 64(211-212), 143-152.

Kohn, M. L., \& Schooler, C. (1982). Job conditions and personality: A longitudinal assessment of their reciprocal effects. American journal of Sociology, 87(6), 1257-1286.

Kumar, M., \& Santoro, D. (forthcoming). Being Bound to Fail. How Epistemic Injustice Fails Educational Opportunities.

Lane, R. E. (1991). The market experience. Cambridge: Cambridge University Press.

Lamont, J., \& Favor, C. (2013). Distributive Justice. In E. N. Zalta (Ed.), Stanford Encyclopedia of Philosophy (Spring 2013 Edition). Stanford: Stanford University.

Lepisto, D. A., \& Pratt, M. G. (2017). Meaningful work as realization and justification: Toward a dual conceptualization. Organizational Psychology Review, 7(2), 99-121.

Lips-Wiersma, M., \& Morris, L. (2009). Discriminating between 'meaningful work'and the 'management of meaning'. Journal of Business Ethics, 88(3), 491-511.

Louwaars, N. (2007). Seeds of confusion: the impact of policies on seed systems: PhD thesis, Wageningen Universiteit.

Lucas, K. (2015). Workplace Dignity: Communicating Inherent, Earned, and Remediated Dignity. Journal of Management Studies, 52(5), 621-646.

May, D. R., Li, C., Mencl, J., \& Huang, C.-C. (2014). The ethics of meaningful work: Types and magnitude of job-related harm and the ethical decision-making process. Journal of Business Ethics, 121(4), 651-669.

Mijs, J. J. (2016). The unfulfillable promise of meritocracy: three lessons and their implications for justice in education. Social Justice Research, 29(1), 14-34.

Moellendorf, D. (2006). Equality of opportunity globalized. Canadian Journal of Law \& Jurisprudence, 19, 301-318.

Murnion, W. E. (1989). The ideology of social justice in economic justice for all. Journal of Business Ethics, 8(11), 847-854.

Narisada, A. (2017). Socioeconomic Status and the Relationship Between Under-Reward and Distress: Buffering-Resource or Status-Disconfirmation? Social Justice Research, doi: 10.1007/s11211017-0288-z.

Nozick, R. (1974). Anarchy, state, and Utopia. New York: Basic Books.

Offe, C. (2009). Basic Income and the Labor Contract. Analyse \& Kritik, 31(1), 49-79.

Ooms, G. (2010). Why the West is perceived as being unworthy of cooperation. Journal of Law, Medicine and Ethics, 38(3), 594-613.

Otsuka, M. (2008). Freedom of occupational choice. Ratio, 21(4), 440-453. 
Parr, T. (2015). From philanthropy to philanthropists. In B. Morvaridi (Ed.), New Philanthropy and Social Justice: Debating the Conceptual and Policy Discourse (pp. 64-77). Bristol: Policy Press.

Pogge, T. W. (2008). World poverty and human rights : cosmopolitan responsibilities and reforms (2nd ed.). Cambridge: Polity.

Rawls, J. (1999). A theory of justice (Rev. ed.). Cambridge, Mass.: Belknap Press of Harvard University Press.

Robeyns, I. (2011). The Capability Approach. In E. N. Zalta (Ed.), Stanford Encyclopedia of Philosophy (Summer 2011 Edition). Stanford: Stanford University.

Roessler, B. (2012). Meaningful Work: Arguments from Autonomy. Journal of Political Philosophy, 20(1), 71-93.

Sarkin, J., \& Koenig, M. (2011). Developing the right to work: intersecting and dialoguing human rights and economic policy. Human Rights Quarterly, 33(1), 1-42.

Sayer, A. (1989). Postfordism in question. International Journal of Urban and Regional Research, 13(4), 666-695.

Sayer, A. (2009). Contributive justice and meaningful work. Res Publica, 15, 1-16.

Sayer, A. (2011). Habitus, work and contributive justice. Sociology, 45(1), 7-21.

Sayer, A. (2012). Capabilities, Contributive Injustice and Unequal Divisions of Labour. Journal of Human Development and Capabilities, 13(4), 580-596.

Schaff, K. P. (2012). Democratic Rights in the Workplace. Inquiry, 55(4), 386-404.

Schwartz, A. (1982). Meaningful work. Ethics, 92(4), 634-646.

Schweiger, G. (2013). Recognition and social exclusion. A recognition-theoretical exploration of poverty in Europe. Ethical Perspectives, 20(4), 529-554.

Sen, A. (2001). Development as freedom. Oxford: Oxford University Press.

Sen, A. (2009). The idea of justice. Cambridge, MA: Harvard University Press.

Sennett, R. (2008). The craftsman. New Haven \& London: Yale University Press.

Shaheed, F. (2012). Report of the Special Rapporteur in the field of cultural rights. United Nations (A/HRC/20/26).

Shaver, L. (2010). The right to science and culture. Wisconsin Law Review, 121, 121-184.

Shiffrin, S. V. (2003). Race, labor, and the fair equality of opportunity principle. Fordham Law Review, 72, 1643-1675.

Sison, A. J. G., Ferrero, I., \& Guitián, G. (2016). Human Dignity and The Dignity of Work: Insights from Catholic Social Teaching. Business Ethics Quarterly.

Sklair, L. (2016). The Transnational Capitalist Class, Social Movements, and Alternatives to Capitalist Globalization. International Critical Thought, 6(3), 329-341.

Snyder, J. (2010). Exploitation and sweatshop labor: Perspectives and issues. Business Ethics Quarterly, 20(02), 187-213.

Sparrow, R., \& Goodin, R. E. (2001). The Competition of Ideas: Market or Garden? Critical Review of International Social and Political Philosophy, 4(2), 45-58. 
Spencer, D. A. (2013). Promoting high quality work: obstacles and opportunities. Journal of Business Ethics, 114(3), 583-597.

Stanczyk, L. (2012). Productive justice. Philosophy \& Public Affairs, 40(2), 144-164.

Steger, M. F. (2017). Creating Meaning and Purpose at Work. In: The Wiley Blackwell Handbook of the Psychology of Positivity and Strengths-Based Approaches at Work (pp. 60-81). Hoboken: John Wiley \& Sons.

Sturn, R. (2009). Volenti Non Fit Iniuria? Contract Freedom and Labor Market Institutions. Analyse und Kritik, 31(1), 81-99.

Tablan, F. (2015). Catholic social teachings: Toward a meaningful work. Journal of Business Ethics, 128(2), 291-303.

Taka, I., \& Foglia, W. D. (1994). Ethical aspects of "Japanese leadership style”. Journal of Business Ethics, 13(2), 135-148.

Taylor, C. (1994). The politics of recognition. In A. Gutmann (Ed.), Multiculturalism: Examining the politics of recognition (pp. 25-74). Princeton: Princeton University Press.

Taylor, R. (2004). Self-realization and the priority of fair equality of opportunity. Journal of Moral Philosophy, 1(3), 333-347.

Terzi, L. (2007). The capability to be educated. In M. Walker, \& E. Unterhalter (Eds.), Amartya Sen's Capability Approach and Social Justice in Education (pp. 25-43). New York \& Basingstoke: Palgrave Macmillan.

Tight, M. (1998). Lifelong learning: opportunity or compulsion? British Journal of Educational Studies, 46(3), 251-263.

Timmermann, C. (2014). Sharing in or benefiting from scientific advancement? Science and Engineering Ethics, 20(1), 111-133.

Timmermann, C., \& Belt, H. v. d. (2012). Global justice considerations for a proposed "Climate Impact Fund". Public Reason, 4(1-2), 182-196.

Timmermann, C., \& Félix, G. F. (2015). Agroecology as a vehicle for contributive justice. Agriculture and Human Values, 32(3), 523-538.

United States Catholic Bishops (1997). Economic Justice for All: Pastoral Letter on Catholic Social Teaching and the U.S. Economy. Washington, DC: United States Conference of Catholic Bishops.

Valente, R. R., \& Berry, B. J. (2016). Working hours and life satisfaction: A cross-cultural comparison of Latin America and the United States. Journal of Happiness Studies, 17(3), 1173-1204.

Van Parijs, P. (1997). Real freedom for all: What (if anything) can justify capitalism? Oxford: Oxford University Press.

Veltman, A. (2016). Meaningful work. New York: Oxford University Press.

Via Campesina (1996). The right to produce and access land. Rome: Via Campesina.

Walsh, A. J. (1994). Meaningful work as a distributive good. The Southern journal of philosophy, $32(2), 233-250$.

Walzer, M. (1983). Spheres of justice: A defense of pluralism and equality. New York: Basic Books. Wolf, S. (2010). Meaning in life and why it matters. Princeton: Princeton University Press. 
Wolff, J. (2004). Training, Perfectionism and Fairness. Journal of applied philosophy, 21(3), 285-295.

Yeoman, R. (2014). Conceptualising Meaningful Work as a Fundamental Human Need. Journal of Business Ethics, 125(2), 235-251.

Young, I. M. (2004). Responsibility and Global Labor Justice. Journal of Political Philosophy, 12(4), 365-388.

Ziegler, J. (2011). Destruction massive: Géopolitique de la faim. Paris: Seuil.

Ziegler, R. (2011). Fair competition of ideas. Paper presented at the Responsible Innovation Conference, The Hague, April 18-19, 2011. 